\title{
Mate as Dietary Supplement for Broiler Chickens: Effect on the Metabolic Profile and Redox Chemistry of Meat
}

\author{
Caroline Ceribeli, ${ }^{a}$ Andressa de Zawadzki, ${ }^{a, b}$ Aline M. C. Racanicci, ${ }^{c}$ Luiz A. Colnago, ${ }^{d}$ \\ Leif H. Skibsted ${ }^{b}$ and Daniel R. Cardoso*,a
}

${ }^{a}$ Instituto de Química de São Carlos, Universidade de São Paulo, Av. Trabalhador São-Carlense, 400, CP 780, 13560-970 São Carlos-SP, Brazil

${ }^{b}$ Department of Food Science, University of Copenhagen, Rolighedsvej 26, DK-1958 Frederiksberg C, Denmark

${ }^{c}$ Faculdade de Agronomia e Medicina Veterinária, Universidade de Brasília, Campus Darcy Ribeiro, 70910-970 Brasília-DF, Brazil

${ }^{d}$ Embrapa Instrumentação Agropecuária, Rua 15 de Novembro, 1452, 13560-970 São Carlos-SP, Brazil

\begin{abstract}
Moderate supplementation with extract of mate to a standard broiler diet in feeding experiment with 5 treatment groups was found to increase production of endogenous antioxidants in muscles, improving meat quality and storage stability. For addition of 250 or $500 \mathrm{mg}$ extract per $\mathrm{kg}$ feed, pre-cooked meatballs made from the breast muscles had a significant lower level of secondary lipid oxidation products during one week of chill storage. Addition of 750 or $1000 \mathrm{mg}$ extract per $\mathrm{kg}$ feed had an increasing prooxidative effect during storage of the meatballs. For the moderate levels of plant phenols in feed, a metabolic study based on nuclear magnetic resonance (NMR) spectroscopy of meat extracts showed that mate extract added to the feed increased the muscle level of antioxidative peptides like anserine, while indication of toxic effects was noted for the higher levels of feed additives. Rate of formation of radicals as detected by electron paramagnetic resonance (EPR) spectroscopy was found to correlate with the oxidative damage and a kinetic analysis demonstrated that the antioxidative effect of mate supplemented to the feed could be assigned to radical scavengers present in the meat. These findings for the monogastric animals are different from results previously obtained for ruminants, where plant phenols rather seem to affect the microflora of the digestive tract.
\end{abstract}

Keywords: mate, chicken meat, metabolomics, broiler diet

\section{Introduction}

Plant extracts have been used as food preservatives and animal feed additives for the production of meat-based products aiming to prevent nutritional loss and quality deterioration. Extract of several plants are rich in phenolic compounds being a natural source of antioxidants and may be added directly to the meat through injectionenhancement in order to inhibit oxidative pathways. ${ }^{1-10}$ The antioxidant mechanisms of the phenolic compounds include radical scavenging and metal chelating activity. ${ }^{1,6}$ On the other hand, several studies have demonstrated that the addition of plant extracts in animal feed promotes a positive

*e-mail: drcardoso@iqsc.usp.br response in the animal metabolism improving animal health and performance, and yielding high concentrations of endogenous antioxidants in the muscle, consequently improving the overall redox stability of meat.

One example of a plant extract with potential applications in the meat production is the extract of mate (Ilex paraguariensis). Widely consumed as an infused beverage in South America due to its positive effects for human health, mate is composed of a high amount of phytochemical compounds, in which the major compounds are phenolics, saponins, and methylxantines. The antioxidant effect of the phenolic compounds from mate extract in preventing meat oxidation has been largely reported in literature. Suitable levels of mate extract have been shown to protect lipids and proteins 
against oxidation when added to brine-injected retailpacked pork chops and were found to improve sensory aspects of meat when compared to ascorbic acid, which is the most common antioxidant additive for injectionenhancement. ${ }^{11,12}$ The addition of mate extract to cattle feed improved sensory aspects like tenderness and consumer acceptance. Moreover, an enhanced redox stability of meat was achieved in beef from cattle fed $1.5 \% \mathrm{~m} / \mathrm{m}$ mate and was found to be related to the modulation of the animal metabolism in order to produce increased concentrations of endogenous antioxidants like carnosine, anserine and conjugated linoleic acid. ${ }^{13}$ The effect of mate on animal performance and oxidative stability in chicken meat was reported by Racanicci et al. ${ }^{14,15}$ The addition of mate added to drinking water for broiler chickens was not shown to affect the content of lipids in chicken breast meat, but positively influenced the protection of lipid against oxidation, as indicated by a lower content of thiobarbituric acid-reactive substances (TBARS).

Therefore, mate extract can potentially be used as supplement for animal nutrition in order to provide improvement of animal health, consequently benefitting the quality of meat. Despite the fact that the effect of mate extract on animal performance and lipid oxidation in meat from broiler chicken has been previously reported, the influence of mate on chicken meat metabolism has not been previously investigated. Herein, we investigated the effect of adding increasing levels of mate extract to chicken feed on the meat metabolomics, redox stability of meat and lipid oxidation.

\section{Experimental}

\section{Mate extracts}

The extract of mate leaves was obtained from Centroflora Group (Botucatu, SP, Brazil). The mate extract was prepared from fresh leaves by extraction with water/ ethanol $(75: 25, \mathrm{v} / \mathrm{v})$ at $90{ }^{\circ} \mathrm{C}$. The extract was dried in spray-drier tower.

Ultra performance liquid chromatography (UPLC) coupled to high resolution mass spectrometry (HRMS) were used for the characterization of the phenolic compounds of mate extract. Methanol/water $(1: 1, \mathrm{v} / \mathrm{v})$ solutions of mate extract were prepared using a commercial cell disruptor (Fast Prep ${ }^{\circledast}$, MP Biomedicals), filtered using nylon membranes of $0.45 \mathrm{~mm}$ and stored at $-20^{\circ} \mathrm{C}$ until the UPLC-high resolution electrospray ionization (HRESI)-MS analysis. Sample extracts of $10 \mu \mathrm{L}$ were injected into an Accela 1250 high performance liquid chromatography (HPLC) system coupled with an Accela AS autosampler and a high-resolution accurate mass spectrometer LTQ OrbitrapVelos (Thermo Fisher Scientific), which was equipped with an electrospray source (HESI-II) operating in the negative ion detection mode. A flow rate of $0.5 \mathrm{~mL} \mathrm{~min}^{-1}$ was used and its mobile phase consisted of a linear gradient from 5\% of mobile phase B (methanol containing 0.1\% formic acid) and $95 \%$ of mobile phase $\mathrm{A}(0.1 \%$ aqueous formic acid) to $80 \%$ of mobile phase B over $30 \mathrm{~min}$ and then from 80 to $95 \%$ of mobile phase B in 5 min which was held 5 min isocratic. Finally, the mobile phase B was decreased from 95 to $5 \%$ of B in $7 \mathrm{~min}$.

\section{Broiler feeding trials}

Animal feeding trials were carried out under the ethical requirements from the institutional animal care and use committee of the Escola Superior de Agricultura "Luiz de Queiroz" (ESALQ), Universidade de São Paulo. 1440 female Cobb chickens (1-day old) were randomly divided into five groups and allotted five different treatments according to the level of additive (vitamin E or mate extract). All birds were fed ad libitum a basal diet ${ }^{16}$ based on corn, soybean meal (45\%), soybean oil, dicalcium phosphate, limestone, sodium chloride, $D L$-methionine $99 \%, L$-lysine $\mathrm{HCl} 78 \%$, inert carrier material, vitamin and mineral supplement, choline chloride $60 \%, L$-threonine $98.5 \%$, and anticoccidial. An appropriate level of additive was used for each treatment. In treatment 1 (T1), negative control: no antioxidants were used in the feed; treatment 2 (T2): $125 \mathrm{mg}$ of vitamin E per $\mathrm{kg}$ of food were used. Vitamin E was obtained as the commercial product Microvit E Promix 50 (Adisseo Company), which is composed of $D L$-alpha tocopheryl acetate $(\alpha$-toc) adsorbed onto an expanded silica carrier; treatment 3 (T3): $250 \mathrm{mg}$ of mate extract per $\mathrm{kg}$ of food; treatment 4 (T4): $750 \mathrm{mg}$ of mate extract per $\mathrm{kg}$ of food; and treatment 5 (T5): $1000 \mathrm{mg}$ of mate extract per $\mathrm{kg}$ of food.

Broilers were fed from 1 to 38 days of age according to each diet and then slaughtered. ${ }^{17}$ Breast meat was collected, deboned and part of the samples was vacuum-packed and stored in a freezer at $-80{ }^{\circ} \mathrm{C}$ until analysis. Meatballs were prepared just after the breast meat samples had been collected. ${ }^{18}$ Fifteen samples, with three samples from each of the five treatments (A, B and C), were selected for the metabolomics and redox stability analyses.

\section{Measurement of lipid oxidation}

Defrosted breast meat samples were minced and homogenized with $0.5 \%$ food-grade salt to produce meatballs $(30 \pm 0.5 \mathrm{~g})$. Breast meatballs were vacuumpacked and pre-cooked in water $\left(100{ }^{\circ} \mathrm{C}\right)$ for $10 \mathrm{~min}$, 
according to Racanicci et al. ${ }^{14}$ Pre-cooked meatballs were repacked in oxygen-permeable bags and stored chilled $\left(4{ }^{\circ} \mathrm{C}\right)$ in the dark for 8 days. Secondary lipid oxidation products (malondialdehyde (MDA)) were evaluated in duplicate on days $0,2,4,6$ and 8 of chilled storage using the TBARS method according to Madsen et al. ${ }^{19}$ Absorbance was measured at 532 and $600 \mathrm{~nm}$ using a UV-340G spectrophotometer (Gehaka) and the difference $\left(\mathrm{A}_{532 \mathrm{~nm}}-\mathrm{A}_{600 \mathrm{~nm}}\right)$ was used in order to correct the absorbance for turbidity. Results were expressed in $\mu$ mol MDA per $\mathrm{kg}$ of meat, using a 1,1,3,3-tetraethoxypropane (TEP) standard curve.

Extraction of the polar metabolites from chicken meat and nuclear magnetic resonance (NMR) metabolomics analysis

High-resolution ${ }^{1} \mathrm{H}$ NMR spectroscopy was performed on the extracts of chicken meat in order to determine the profile of polar metabolites. Chicken meat $(0.10 \mathrm{~g})$ was homogenized for 1 min using a commercial cell disruptor (FastPrep ${ }^{\circledR}$, MP Biomedicals) with $1.0 \mathrm{~mL}$ of methanol/ water solution (1:1) in homogenization tubes containing ceramic beads. Homogenates were centrifuged for $10 \mathrm{~min}$ at $10,000 \mathrm{~g}$ at $10{ }^{\circ} \mathrm{C}$. Supernatant was carefully collected and transferred to Eppendorf tubes, and then dried in a centrifugal concentrator (Speed-Vac, Thermo Savant). Pellets were collected and re-suspended with $0.05 \mathrm{M}$ deuterium oxide-formate buffer (pD 4.1; Sigma-Aldrich) containing $1 \mathrm{mM}$ of the internal chemical shift standard 3-trimethylsilyl-2,2,3,3- $d_{4}$-propionate (TMSP- $d_{4}$; SigmaAldrich), and transferred to $5 \mathrm{~mm}$ NMR tubes.

Extracts of chicken meat were analyzed by highresolution ${ }^{1} \mathrm{H}$ NMR spectroscopy using an Agilent DD2 spectrometer with a magnetic field of $11.7 \mathrm{~T}(499.84 \mathrm{MHz}$ for hydrogen frequency). The temperature was kept constant at $298 \mathrm{~K}$ throughout the NMR analysis. NMR experiments were performed using a pulse of $\pi / 6$ and 64 transients were collected into 32768 complex points spanning a spectral width of $14 \mathrm{ppm}$ and relaxation delay of $4 \mathrm{~s}$, and the pulse sequence with water presaturation PRESAT (Agilent Technologies) was employed to suppress the water peak. Spectra were processed by phase and baseline correction and by the calibration of the internal chemical shift standard TMSP- $d_{4}$ at 0 ppm using VnmrJ 4.0 software (Agilent Technologies).

Polar metabolites present in the meat extract were identified in the NMR spectra by use of the database present in the Chenomx NMR Suite 8.0 software. ${ }^{20}$ From the assignment of the peaks in the NMR spectra, the polar metabolites were quantified using the $500 \mathrm{MHz}$ library from Chenomx NMR Suite 8.0 by reference to the TMSP- $d_{4}$ concentration as $1 \mathrm{mM}$. Standard solutions from carnosine, adenine, hypoxanthine, adenosine, inosine, adenosine 5'-triphosphate and inosine 5'-monophosphate (Sigma-Aldrich), and a mixture of these solutions in $1 \mathrm{mM}$ concentration were used in order to validate some of the metabolites. Additionally, ChemSpider ${ }^{21}$ and Human Metabolome Database (HMDB) ${ }^{22}$ were used..$^{23-25}$

\section{Multivariate analysis}

Untargeted metabolomics were performed on the NMR spectra of the chicken meat extracts to investigate possible clustering of the samples as function of the diet. NMR datasets reported as time-domain free induction decay (FID) were converted into a frequency-amplitude table by the use of the complete reduction to amplitude frequency table (CRAFT) technique. CRAFT corresponds to a Bayesian approach for NMR spectral analysis provided as a toolbox included in the packages of the VnmrJ 4.0 software (Agilent Technologies). ${ }^{26}$

Multivariate data analyses were performed on Weka software ${ }^{27,28}$ using the information gain (IG) method $^{29}$ on the data taken from the table of frequency, amplitude and linewidth as extracted from CRAFT software. The IG method provided a ranking of peaks in the NMR spectra that are of importance to discriminate the samples (FIDs), allowing the selection of the most suitable variables. Subsequently, principal component analysis $(\mathrm{PCA})^{30}$ was performed to graphically represent the multidimensional data through the reduction of dimensionality based in the higher co-variance among the samples. Python ${ }^{31}$ was used to compute the results of the PCA.

Electron paramagnetic resonance (EPR) spin-trapping and redox stability of meat

The spin-trapping EPR technique was used to investigate the redox stability of meat by monitoring the $\alpha$-tert-butylphenylnitrone (PBN; Sigma-Aldrich) radical adduct formation in meat slurries incubated at $65^{\circ} \mathrm{C}$. Accordingly, $0.9 \mathrm{~g}$ of chicken breast were homogenized in $6 \mathrm{~mL}$ of $50 \mathrm{mM}$ 2-( $N$-morpholino)ethanesulfonic acid (MES) buffer of pH 5.7 using an Ultra-Turrax homogenizer (Janke \& Kunkel). Then, $400 \mu \mathrm{L}$ of $320 \mathrm{mM}$ PBN dissolved in ethanol were added to the homogenate. Samples were vortexed briefly and then, aliquots of $1 \mathrm{~mL}$ of the solutions were incubated for $0.5,1,2$ and $3 \mathrm{~h}$ at $65^{\circ} \mathrm{C}$. Afterwards, the aliquots were centrifuged for $10 \mathrm{~min}$ at $10,000 \mathrm{rpm}$ and $10^{\circ} \mathrm{C}$, and maintained at the temperature of ice before recording the EPR spectra. Solutions were transferred through a flowing system to a $50 \mu \mathrm{L}$ micropipette 
(Blaubrand Intramark) located in the EPR cavity of an EMXplus EPR spectrometer (Bruker BioSpin). The X-band EPR spectra of the chicken slurries were obtained at room temperature, with the following parameters: microwave power: $10 \mathrm{~mW}$; sweep width: $100.00 \mathrm{G}$; center field: $3480.00 \mathrm{G}$; modulation frequency: $100.00 \mathrm{kHz}$; modulation amplitude: $1.00 \mathrm{G}$, and $\mathrm{n}=16$ scans.

Spectra were processed using Win EPR Processor software (Bruker BioSpin). Relative EPR intensities, obtained by double integration of the first signal of each spectrum, were plotted against time in order to determine the kinetic behavior of the formation of radicals. A least square method ${ }^{32}$ was used to plot the experimental datasets and the curves representing the time-dependence of the radical formation were adjusted by non-linear regression fitting.

\section{Results and Discussion}

\section{Untargeted NMR metabolomics}

Metabolite fingerprints of the meat extracts were established from the evaluation of the full NMR spectral profile. The ${ }^{1} \mathrm{H}$ NMR spectrum is composed of a wide range of signals that were assigned to all the NMR-detectable metabolites of meat extracts. Each metabolite is found as a set of signals with characteristic chemical shifts and multiplicities in the NMR spectrum. As presented in Figure 1, several polar metabolites of relevance for meat quality were identified in the ${ }^{1} \mathrm{H}$ NMR spectrum of the chicken meat extracts. Meat extracts from different feeding groups did not show significant differences in the
NMR spectral profile. However, differences in the relative intensity of the signals were observed when comparing the spectra of the samples corresponding to the negative control with the samples from animals fed with mate extract (Figure S1, Supplementary Information (SI) section).

Differences in the relative intensity of NMR peaks provided insight into the effect of feeding regimes on the quality aspects of meat because the intensity of the signals in the ${ }^{1} \mathrm{H}$ NMR spectra is associated with the concentration of the polar metabolites in the meat extracts. Relative intensities of the NMR signals were numerically represented by signal amplitude. Then, CRAFT was used in the time-domain spectral analysis to compare different feeding treatments. The conversion of frequency into chemical shift was also carried out for a better assignment of the polar metabolites throughout the CRAFT datasets.

The IG method in conjunction with PCA was performed on the full dataset obtained from CRAFT in order to identify the spectral regions responsible for possible clustering of the samples. Initially, the IG method was used for attribute selection and the NMR signals were classified according to their importance for discriminating the samples. Figure 2 presents the signals or chemical shifts of relevance for each treatment. In T1, signals at 2.64 ( $\beta$-alanine), 3.22 (peak not assigned), 2.73 (carnosine), 3.77 (alanine), 3.85 (anserine), 0.95 (peak not assigned) and $4.52 \mathrm{ppm}$ (carnosine) were identified as the attributes with similar amplitudes among the samples of this treatment and with different amplitudes when compared to the samples from other treatments. The signal at $3.77 \mathrm{ppm}$ was of high intensity for only one sample of T1 (animal B). Signals at 4.51 (adenosine triphosphate (ATP), adenosine diphosphate

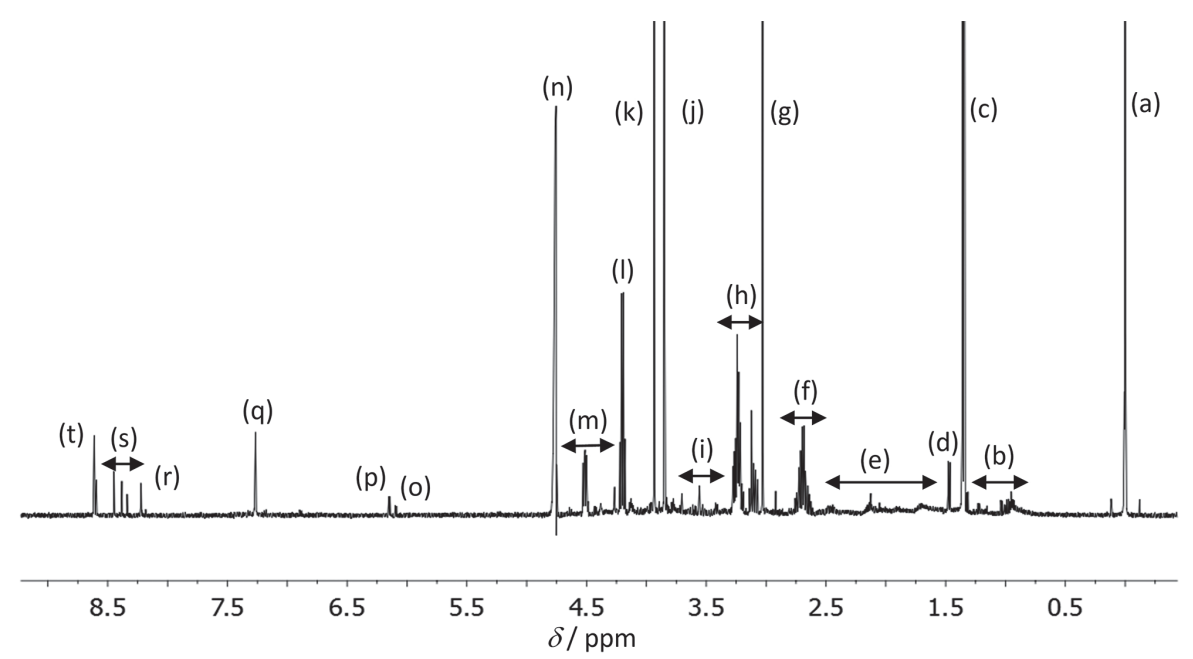

Figure 1. Typical ${ }^{1} \mathrm{H}$ NMR spectrum of meat extract from chicken fed T1 ( $0 \%$ of mate extract) with the assignment of the signals. (a) TMSP- $d_{4}$; (b) isoleucine, leucine, valine and threonine; (c) and (l) lactate; (d) alanine; (e) leucine, isoleucine, acetate, glutamate, methionine and valine; (f) methionine, $\beta$-alanine, anserine and carnosine; $(\mathrm{g})$ and $(\mathrm{k})$ creatine; (h) anserine, carnosine, creatinine, $\beta$-alanine, taurine and betaine; (i) taurine, glycine, threonine, valine, isoleucine, leucine, glutamate, alanine and inosine; (j) anserine, methionine and betaine; (m) threonine, ATP, inosine, creatinine, carnosine and anserine; (n) water; (o) inosine; (p) ATP; (q) carnosine and anserine; (r) inosine and anserine; (s) inosine, formate and ATP; and (t) carnosine and ATP. 
(ADP) and adenosine monophosphate (AMP)), 2.70 (peak not assigned), 0.94 (leucine), 3.77 and $3.85 \mathrm{ppm}$ showed similar amplitudes in the samples of T2. However, the signal at $2.70 \mathrm{ppm}$ stood out from T2 cluster particularly for the animal A of this treatment. In T3, the predominant signals were observed at 4.51, 2.65 (methionine), 2.73, 3.89 (inosine) and $4.52 \mathrm{ppm}$ (which was found as a predominant signal mainly for the animal B of this group). In treatment 4 , a significant coherence was observed for samples A, B and C since the signals at 4.51, 3.22, 2.65, $2.73,3.77,3.85$ and $4.52 \mathrm{ppm}$ showed the most similar amplitudes in these samples when compared to other treatments. In treatment 5, signals at 2.64, 4.49 (anserine),

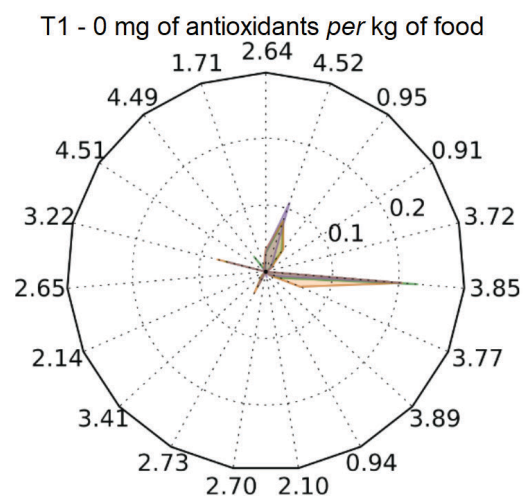

T3 - $250 \mathrm{mg}$ of yerba mate per $\mathrm{kg}$ of food
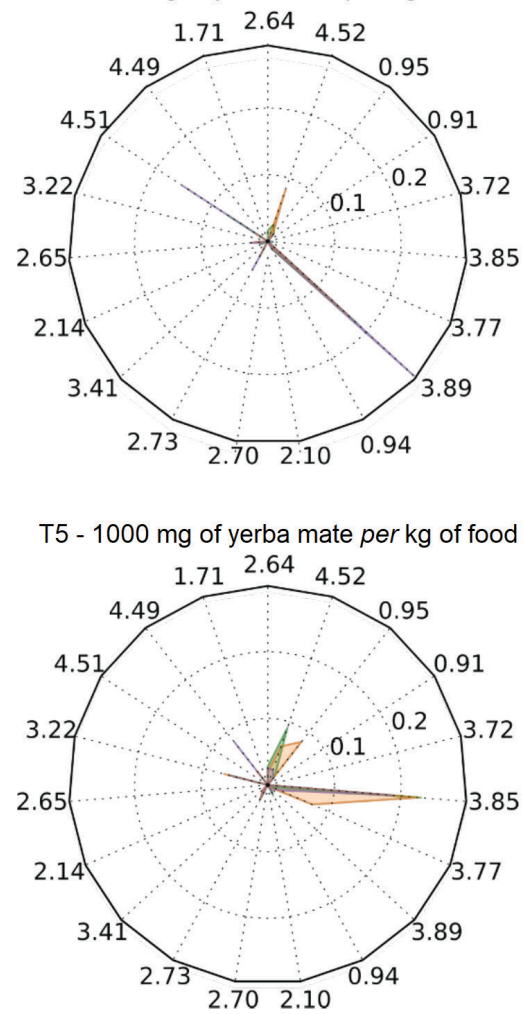

$3.22,2.73,0.94,3.77,3.85,0.95$ (peak not assigned) and $4.52 \mathrm{ppm}$ were of importance for discrimination of these samples from the other feeding regimes. Signals at 3.77 and $0.95 \mathrm{ppm}$ presented the predominant intensities for the animal B in T5.

For each treatment, the predominant signals in the graphic representation of the IG results were concluded to be coherent in the respective treatment. Such signals were effective to discriminate different treatments. This result suggests that animals subjected to the same diet present the same NMR spectral profile and, consequently, the same metabolic profile. Then, PCA was performed using the signals of relevance as variables in order to find the
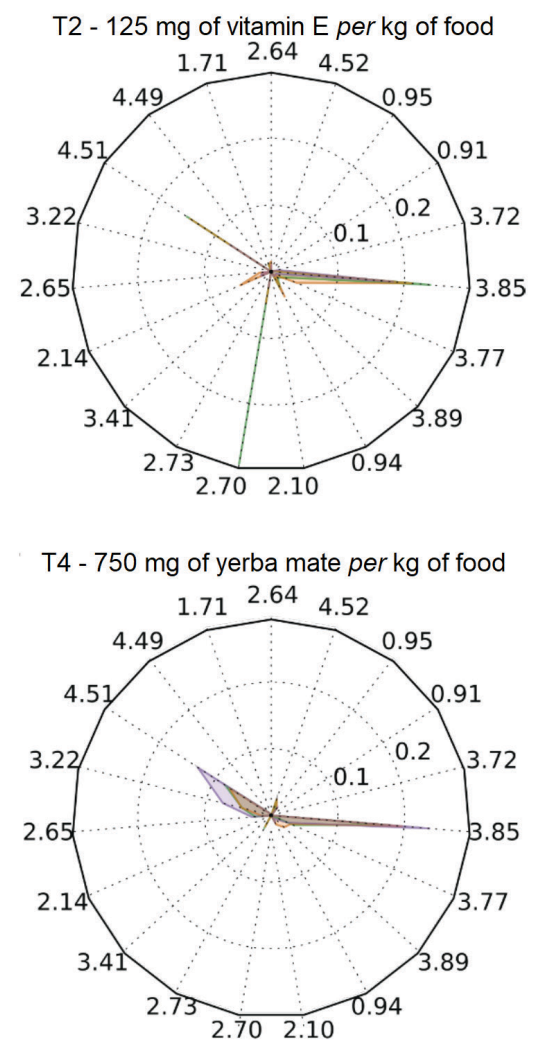
most suitable clustering representation of the IG results (Figure 3; PCA 3D plot).

Following PCA projection, samples of different treatments demonstrated different trends of clustering considering the three principal components PC1, PC2 and PC3. The set of the three first principal components explains $71 \%$ of the total difference among samples of meat extracts (PC1: 39\%; PC2: 21\%; and PC3: 11\%). Loading plots as represented in Figures $4 \mathrm{a}-4 \mathrm{c}$ provide information on the main chemical shifts that are responsible for the variation of the samples in each one of the three principal components. Considering the loading plot associated with PC1 (Figure 4a), chemical shifts at 4.51, 0.94, 3.41, 3.22 and $4.52 \mathrm{ppm}$, corresponding to the metabolites ATP/ADP/AMP, leucine, taurine, a metabolite not assigned, and carnosine, respectively, were found as the most relevant signals to differentiate the metabolite fingerprints of the samples since $\mathrm{PC} 1$ has the highest contribution for the total variation. NMR signals at 3.85 (anserine), 3.89 (inosine), 2.73 (carnosine), 1.71 (metabolite not assigned) and $2.64 \mathrm{ppm}$ ( $\beta$-alanine) were identified as the most relevant peaks in the loading plots for PC2 (Figure 4b). Several
NMR peaks were considered relevant for the variation related to PC3, including the signals at 2.10, 0.91, 1.71, 4.49 and $4.52 \mathrm{ppm}$, representing the metabolites glutamate, isoleucine, signal not assigned, anserine and carnosine, respectively.

Samples of T1, which represents animal fed without antioxidants, are grouped in the positive region of $\mathrm{PC} 1$ and $\mathrm{PC} 3$ and in the negative region of PC2. Isoleucine $(\delta 0.91)$, glutamate $(\delta 2.1)$ and $\beta$-alanine $(\delta 2.64)$ were found as the metabolites responsible for the clustering of the samples from T1 according to the loading plots (Figure 4). Samples of treatment 2 (food supplemented with vitamin E) trended to be clustered in the negative region of PC1 and PC2 and were found around the zero position of PC3. $\delta 1.71,2.14$, 2.70 and 3.72 were the high intensity signals responsible for the clustering of samples of T2. Treatments T3, T4 and T5 are related to the animals fed with different levels of mate extract and, especially T3 and T4, were more cohesive and strongly clustered than the other treatments. It is important to highlight that for all considered PC axis, treatments 2 and 4 are better distinguishable from treatment 1 . Samples from animals fed 250 and $750 \mathrm{mg} \mathrm{kg}^{-1}$ of mate extract (T3
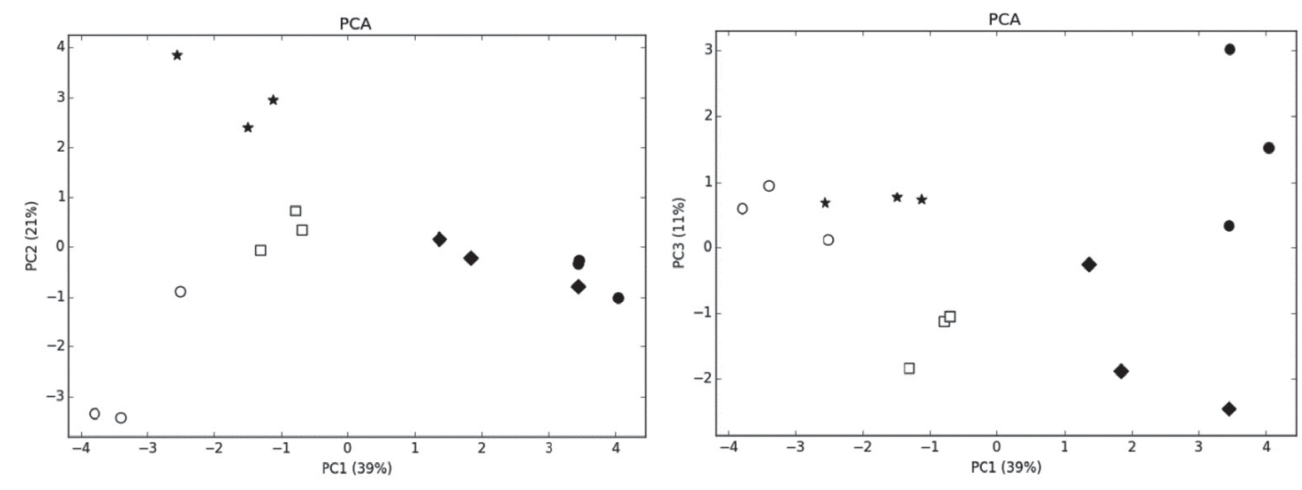

(a)

(b)

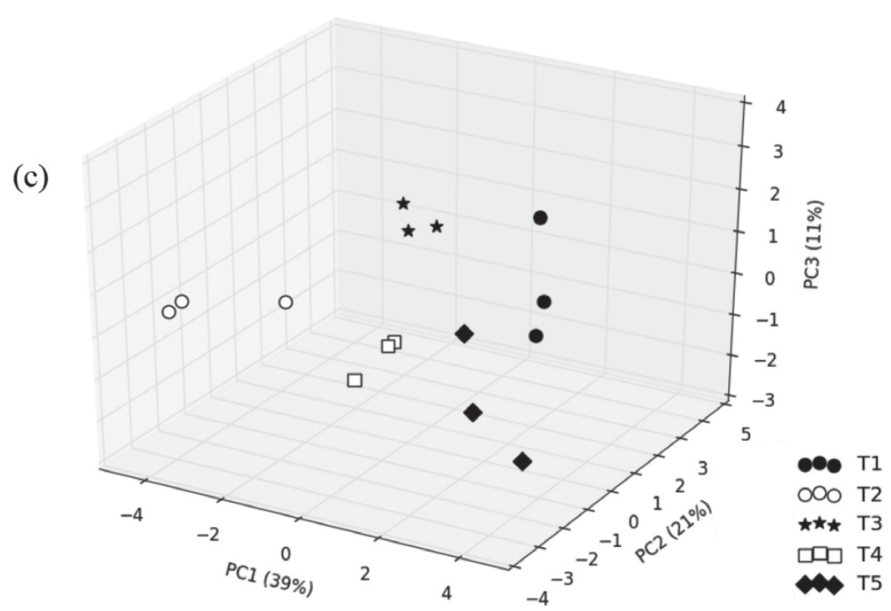

Figure 3. Principal component analysis $(\mathrm{PCA})$ plot constructed from the NMR signals derived from the meat extracts. Subfigures represent: $($ a) PC1 $\times$ PC2; (b) PC1 × PC3; and (c) PC1 × PC2 × PC3 (3D plot). 
and $\mathrm{T} 4$, respectively) presented high levels of methionine and inosine. Loading plots indicated that meat extracts

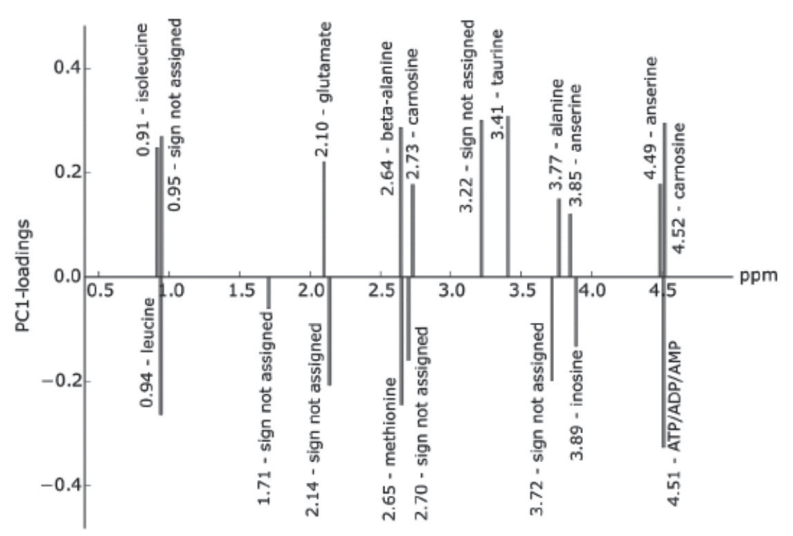

(a)

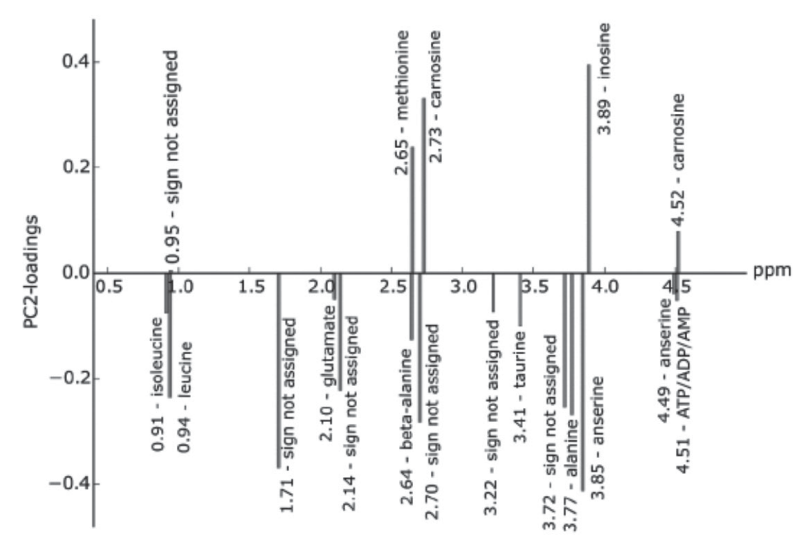

(b)

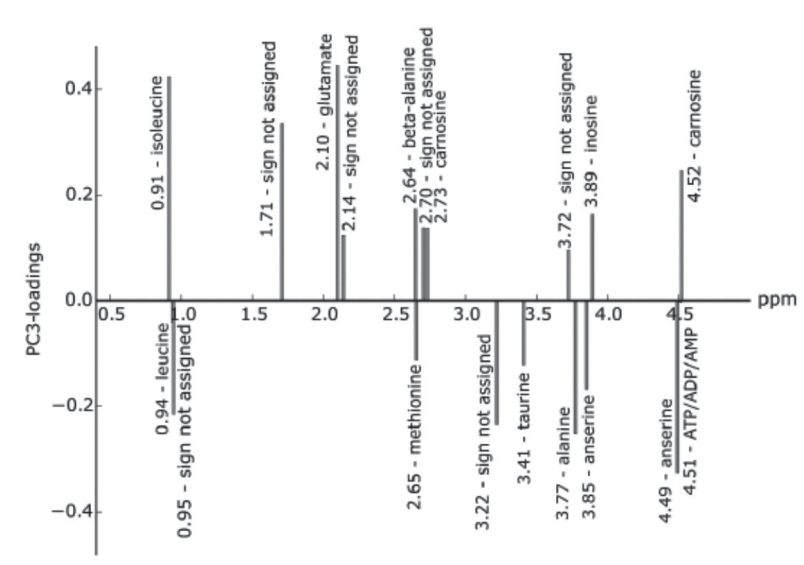

(c)

Figure 4. Loading plots from PCA of meat extracts showing the metabolites responsible for the highest variance associated with (a) PC1, (b) PC2 and (c) PC3. Sign. not assigned: ${ }^{1} \mathrm{H}$ NMR signal could not be assigned to any chemical compound by using the Chemspider ${ }^{21}$ and Human Metabolome Database (HMDB). ${ }^{22}$ from chicken fed $1000 \mathrm{mg} \mathrm{kg}^{-1}$ of mate extract showed high levels of isoleucine, glutamate, alanine, $\beta$-alanine, anserine and of the metabolites with high intensity signals at $\delta 3.22$ and 3.41 .

Quantification of the polar metabolites of meat extracts was carried out from the ${ }^{1} \mathrm{H}$ NMR spectra to assess the effect of mate on the meat composition (Table S1, SI section). Concentrations of lactate, creatine, betaine, ATP/ADP/AMP and formate were found to increase in animals fed vitamin $\mathrm{E}$ and animals fed the lowest level of mate extract (T3) when compared to control animals (T1). However, concentrations of the same metabolites were found to decrease with increasing levels of mate extract from T3 to T5 when comparing animals fed different levels of mate extract. Notably, T1 and T5 exhibit similar concentrations of lactate, creatine, betaine, ATP/ADP/AMP, formate, $\beta$-alanine, carnosine, anserine, creatinine, acetate and threonine. Such similarity between $\mathrm{T} 1$ and $\mathrm{T} 5$ may be also evidenced in the PCA scores plot which shows that samples from $\mathrm{T} 1$ and $\mathrm{T} 5$ are both located in the positive-value region of PC1 and negative-value region of PC2 (Figure 3a). Comparing meat extracts from control animals to the meat extracts from animals fed different levels of mate extract, the main difference in the quantitative metabolite profile was obtained using the lowest level of mate (T3). Zawadzki et al. ${ }^{33}$ observed the same dose-response trend in chicken fed different levels of $\beta$-acids, especially considering that chicken fed the lowest level of supplement presented the highest concentrations of $\beta$-alanine, carnosine and anserine. The concentration of the antioxidants carnosine and anserine was found to significantly increase by adding $250 \mathrm{mg} \mathrm{kg}^{-1}$ of mate extract in the diet of broiler chickens. For chicken, the addition of low levels of phytogenic supplements in the diet seems to enhance the production of antioxidants while dietary phytogenics at high levels seem to induce toxic effects in the animal metabolism.

\section{Redox stability of meat as probed by EPR spin trapping}

Radical formation rate was determined using the EPR spin trapping technique, which allows the investigation of the impact of the diet in the redox status of the meat. The development of radicals in meat slurries under thermal incubation occurs due to the presence of oxidizing species from meat, including transition metals (like heme iron and copper) and peroxides. Such radicals have been demonstrated to be produced mainly by lipids $\mathrm{s}^{34,35}$ and proteins $\mathrm{s}^{36,37}$ and were found to be responsible for quality deterioration of meat products. Short-lived free radicals produced in meat cannot be directly detected by EPR. However, by addition reactions to the spin trap PBN, these free radicals yield more stable 
radicals adduct with characteristic patterns of splitting and with suitable lifetimes to be measured by EPR (Figure S2, SI section). Characteristic splitting patterns are found to be the most important parameters for identification of the nature of the radical appearing in meat systems. The EPR spectrum of $\mathrm{PBN}$ adduct radical in meat slurries, as presented in Figure S2, was found as a triple doublet with values of $\mathrm{A}_{\mathrm{N}}=16.00 \mathrm{G}, \mathrm{A}_{\mathrm{H}}=3.34 \mathrm{G}$ and $\mathrm{g}_{\text {iso }}=2.01458$, suggesting the formation of carbon atom centered radical..$^{38}$

Following $3 \mathrm{~h}$ of incubation at $65{ }^{\circ} \mathrm{C}$, the production of radicals took place approximately after a lag phase of $30 \mathrm{~min}$. The signals increased proportionally with time after the incubation period. Using the spin-trapping technique, kinetics for the formation of radicals were determined by the variation of the relative EPR intensity related to the PBN adduct radical as function of the incubation time ${ }^{13}$ (Figure 5). Radical formation rates in meat slurries showed a kinetic behavior that can be described by an exponential growth function. The least square method (Levenberg-Marquardt algorithm $)^{39}$ was used for fitting the kinetic curve data.

The lipid peroxidation cycle was found as a possible mechanism to explain the kinetics behavior of the curves describing the radical formation rate. The model, as represented by Figure 6, has different steps that are associated with the rate constants $\mathrm{k}_{1}, \mathrm{k}_{\mathrm{O} 2}$ and $\mathrm{k}_{2}$. The first step, known as initiation of oxidation, is related to $k_{1}$ and corresponds to the chain reaction for the production of a radical species $B$ from a substrate $A$ in the absence of the spin trap PBN. $\mathrm{k}_{\mathrm{O} 2}$ is associated with the step called propagation of oxidation, which yields intermediate products through the reaction of the radicaloid species B with molecular oxygen. These intermediate products may yield primary products in a final step. The addition of the spin trap PBN in the system allows alternative pathways in the lipid peroxidation cycle. Since PBN was used in

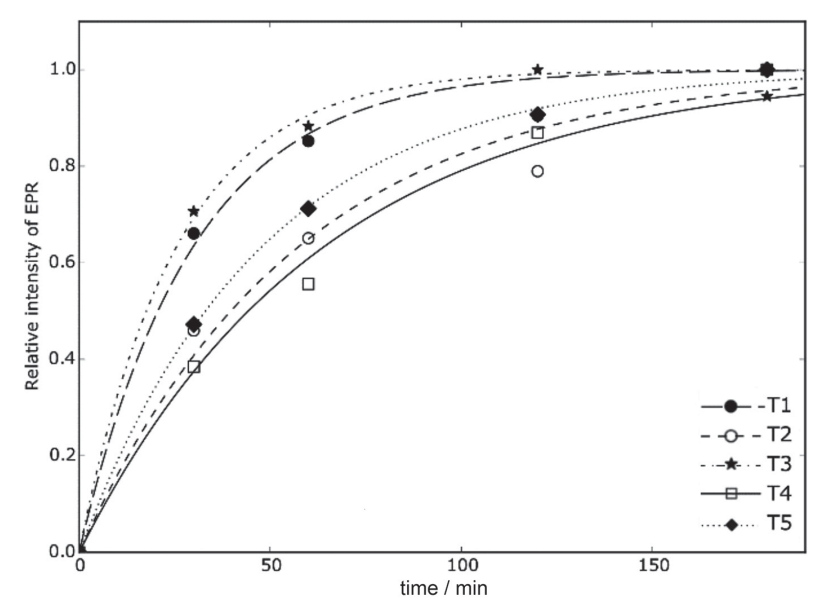

Figure 5. Rate for radical formation in meat slurries from chicken fed with T1, T2, T3, T4, and T5. EPR relative intensities were obtained by double integration of the first peak of the PBN adduct radical spectrum and represent the average of three animals per treatment.

excess $(320 \mathrm{mM})$, the path of consecutive chain reactions is affected towards the formation of the adduct radical C, which is associated with the constant $\mathrm{k}_{2}$. Rate constants $\mathrm{k}_{\mathrm{O} 2}$ and $\mathrm{k}_{2}$ are both diffusion-controlled or close to diffusioncontrolled ( $10^{9}$ and $10^{7}-10^{8} \mathrm{M}^{-1} \mathrm{~s}^{-1}$, respectively).

Taking into account the scheme for the lipid peroxidation cycle of Figure 6, rates for the consumption of each species are defined by three differential equations:

$$
\begin{aligned}
& \frac{\mathrm{d}[\mathrm{A}]}{\mathrm{dt}}=-\mathrm{k}_{1}[\mathrm{~A}] \\
& \frac{\mathrm{d}[\mathrm{B}]}{\mathrm{dt}}=\mathrm{k}_{1}[\mathrm{~A}]-\mathrm{k}_{2}[\mathrm{~B}] \\
& \frac{\mathrm{d}[\mathrm{C}]}{\mathrm{dt}}=\mathrm{k}_{2}[\mathrm{~B}]
\end{aligned}
$$

where $[\mathrm{A}],[\mathrm{B}]$ and $[\mathrm{C}]$ correspond to the concentrations of the substrate, the biological radical yielded from meat

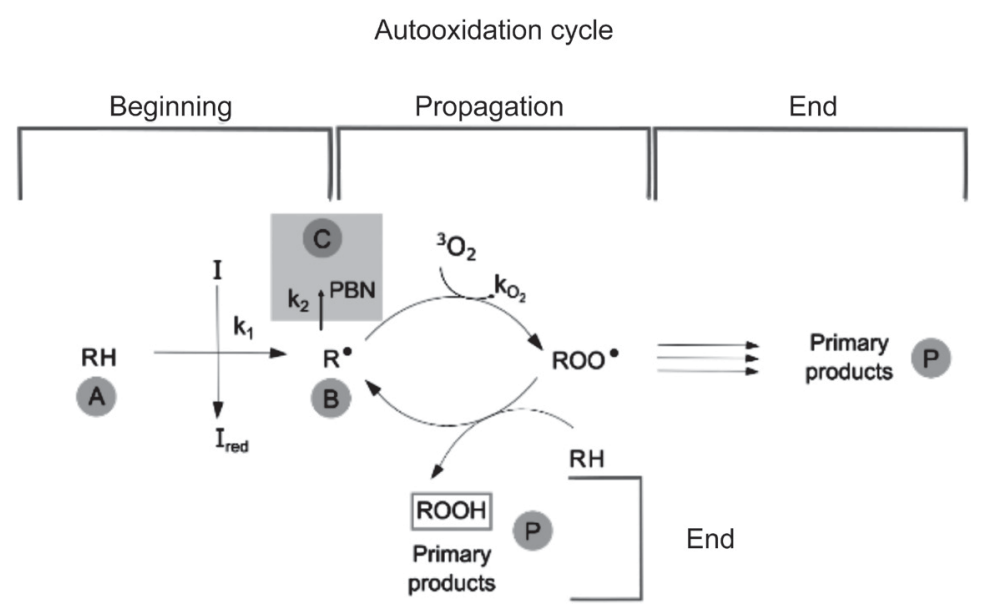

Figure 6. Illustrative autooxidation cycle for radical chain reactions. Autoxidation cycle includes an alternative route, which occurs upon the addition of $\mathrm{PBN}$ to the system resulting in a competitive reaction. 
compounds, and the PBN adduct radical, respectively.

An exponential equation can be obtained from the integration of equation 1 :

$[\mathrm{A}]=\left[\mathrm{A}_{0}\right] \mathrm{e}^{-\mathrm{k}_{1} \mathrm{t}}$

Replacing equation 4 in equation 2 , the following differential equation is obtained:

$\frac{\mathrm{dB}}{\mathrm{dt}}+\mathrm{k}_{2}[\mathrm{~B}]=\mathrm{k}_{1}\left[\mathrm{~A}_{0}\right] \mathrm{e}^{-\mathrm{k}_{1} \mathrm{t}}$

Based on the possible solutions for equation 5 , the concentration of $\mathrm{B}$ can be determined by:

$[\mathrm{B}]=\frac{\mathrm{k}_{1}}{\mathrm{k}_{2}-\mathrm{k}_{1}}\left\{\mathrm{e}^{-\mathrm{k}_{1} \mathrm{t}}-\mathrm{e}^{-\mathrm{k}_{2} \mathrm{t}}\right\}\left[\mathrm{A}_{0}\right]$

Considering that the final concentration of the adduct radical, $[\mathrm{C}]$, corresponds to the initial concentration of the substrate, $\left[\mathrm{A}_{0}\right]$, subtracted by the consumption of the radicals $\mathrm{A}$ and $\mathrm{B},[\mathrm{C}]$ can be calculated as:

$[\mathrm{C}]=\left[\mathrm{A}_{0}\right]-[\mathrm{B}]-[\mathrm{A}]$

Taking into consideration equations 4 and 6, [C] can be determined from equation 7 according to the following expression:

$[\mathrm{C}]=\left(1+\frac{\mathrm{k}_{1} \mathrm{e}^{-\mathrm{k}_{2} \mathrm{t}}-\mathrm{k}_{2} \mathrm{e}^{-\mathrm{k}_{1} \mathrm{t}}}{\mathrm{k}_{2}-\mathrm{k}_{1}}\right)\left[\mathrm{A}_{0}\right]$

Since $k_{2} \gg k_{1}$, in which $k_{1}$ is the limiting step for the formation of radicals, [C] can be estimated in terms of $\mathrm{k}_{1}$ as follows:

$\mathrm{S}_{\mathrm{EPR}} \cong[\mathrm{C}]=\left\{1-\mathrm{e}^{-\mathrm{k}_{1} \mathrm{t}}\right\}\left[\mathrm{A}_{0}\right]$

where $S_{\mathrm{EPR}}$ corresponds to the integral of the EPR signal.

According to the expression in equation 9, [C] is proportional to the EPR signal intensity. The value for the initial concentration of $\mathrm{A}, \mathrm{A}_{0}$, can be assumed as 1 because the relative EPR intensities were normalized by the highest value of the EPR area obtained from the double integration of the first signal of each spectrum. Values of $k_{1}$ were used to estimate radical formation rates for each feeding treatment, as presented in Table 1.

The redox status of meat slurries from broilers fed different levels of mate extract was deduced from the rate constants for the formation of radicals following $\mathrm{k}_{\mathrm{T} 4}<\mathrm{k}_{\mathrm{T} 2}<\mathrm{k}_{\mathrm{T} 5}<\mathrm{k}_{\mathrm{T} 1}<\mathrm{k}_{\mathrm{T} 3}$. The rate constants for radical formation for the different treatments are statistically different at $p=0.05$. The highest and the lowest rate
Table 1. Rate constants for the formation of PBN adduct radicals upon the incubation of meat slurries at $65^{\circ} \mathrm{C}$

\begin{tabular}{lc}
\hline Dietary mate level & $\mathrm{k}^{\mathrm{a}} \times 10^{-2} / \mathrm{min}^{-1}$ \\
\hline T1 (no antioxidants) & $3.4 \pm 0.3$ \\
T2 (125 mg of vitamin E per $\mathrm{kg}$ of food) & $1.7 \pm 0.2$ \\
T3 (250 mg of mate extract per $\mathrm{kg}$ of food) & $3.9 \pm 0.3$ \\
T4 (750 mg of mate extract per $\mathrm{kg}$ of food) & $1.6 \pm 0.1$ \\
T5 (1000 mg of mate extract per $\mathrm{kg}$ of food) & $2.1 \pm 0.1$ \\
\hline
\end{tabular}

${ }^{\mathrm{a}} p$-value $=3.2 \times 10^{-7} . \mathrm{k}$ : rate constant; T1-T5: treatments 1-5.

constants for the formation of radicals in meat slurries were ascribed to T3 and T4, respectively. Notably, the radical formation rate in meat slurries does not decrease with increasing levels of dietary antioxidants, nor seems to be related to high concentration of polar metabolites with antioxidant properties, as could be expected, and has been demonstrated for cattle fed different levels of mate extract and chicken fed different levels of $\beta$-acids. ${ }^{13,33}$ Such behavior may be explained taking into account that the animal metabolism responds differently to the supplement affecting other meat components that are implicated in the meat oxidation, like lipids and proteins. The antioxidant compounds found in the supplement may be metabolized into other metabolites with relevant properties or may pass intact through the intestinal tract to accumulate in different muscle compartments. It is important to highlight that most part of the phenolic compounds of mate may act as antioxidants in the aqueous phase, thus preventing the oxidation of polar metabolites and water-soluble proteins, like sarcoplasmic and myofibrillar proteins. On the other hand, vitamin $\mathrm{E}$ and $\beta$-acids as a fat-soluble compounds may contribute for an improved redox stability of meat lipids. The efficiency of the active compounds of the supplement in preventing meat components against oxidation depends on their solubility in the aqueous or lipophilic compartments. Besides that, different metabolic responses of the use of dietary mate are clearly observed when comparing monogastric animals like chicken with ruminants.

\section{Lipid oxidation}

The determination of TBARS concentration allows assessing the effect of the feeding regime on the lipid oxidation in meat from broiler chickens used in this study. Lipid peroxidation yields primary and secondary products that can be decomposed into end products with low-molecular weight, including MDA, which can be measured from the TBARS assay as described 
Table 2. Secondary lipid oxidation products, measured as TBARS (mg MDA per kg meat), in pre-cooked breast meatballs from broilers fed increasing dietary levels of mate extracts or vitamin $\mathrm{E}$ during the storage period at $4{ }^{\circ} \mathrm{C}$

\begin{tabular}{|c|c|c|c|c|c|c|c|c|c|}
\hline \multirow{3}{*}{ Day } & \multicolumn{5}{|c|}{ TBARS / (mg MDA per kg meat) } & \multirow{3}{*}{$\mathrm{CV}$} & \multirow{2}{*}{\multicolumn{3}{|c|}{ Model $p$-value }} \\
\hline & \multicolumn{4}{|c|}{ Dietary mate level ${ }^{\mathrm{a}}$} & \multirow{2}{*}{$\begin{array}{c}\text { Vitamin }^{\mathrm{a}} \\
125(\mathrm{~T} 2) \\
\end{array}$} & & & & \\
\hline & $0(\mathrm{~T} 1)$ & $250(\mathrm{~T} 3)$ & $750(\mathrm{~T} 4)$ & $1,000(\mathrm{~T} 5)$ & & & Treat & time & Treat $\times$ time \\
\hline 0 & $2.59^{\mathrm{c}}$ & $3.46^{\mathrm{ABC}}$ & $3.88^{\mathrm{A}}$ & $2.71^{\mathrm{C}}$ & 0.23 & 16.8 & $<0.05$ & $<0.01$ & $<0.01$ \\
\hline $2^{\mathrm{b}}$ & 23.22 & 24.83 & 18.75 & 17.98 & 3.23 & 12.1 & $<0.05$ & $<0.01$ & $<0.01$ \\
\hline $4^{c}$ & 46.06 & 37.94 & 33.70 & 31.73 & 5.51 & 9.77 & $<0.05$ & $<0.01$ & $<0.01$ \\
\hline 6 & $66.09^{\mathrm{A}}$ & $42.47^{\mathrm{C}}$ & $40.60^{\mathrm{C}}$ & $56.99^{\mathrm{B}}$ & $8.38^{\mathrm{D}}$ & 7.59 & $<0.05$ & $<0.01$ & $<0.01$ \\
\hline 8 & $82.11^{\mathrm{A}}$ & $56.26^{\mathrm{CD}}$ & $52.82^{\mathrm{D}}$ & $69.27^{\mathrm{B}}$ & $8.29^{\mathrm{A}}$ & 13.3 & $<0.05$ & $<0.01$ & $<0.01$ \\
\hline
\end{tabular}

${ }^{\mathrm{a}}$ Additive levels in treatments 1-5 (T1-T5) in mg per $\mathrm{kg}$ of diet; ${ }^{b}$ linear effect of dietary mate on the TBARS values $\left(y=24.29 x-0.00663 ; \mathrm{R}^{2}=0.49\right.$; $p<0.01)$; clinear effect of dietary mate on the TBARS values $\left(y=43.28 x-0.01316 ; \mathrm{R}^{2}=0.73 ; p<0.01\right){ }^{\mathrm{A}, \mathrm{B}, \mathrm{C}, \mathrm{D}} 1 \mathrm{smeans}$ (least-squares means) with different letters in each line differ ( $p$-value $<0.1$ ). TBARS: thiobarbituric acid-reactive substances; MDA: malondialdehyde; CV: coefficient of variation.

by Tarladgis and co-workers. ${ }^{40}$ The influence of dietary mate on the development of TBARS in pre-cooked breast meatballs during 8 days of storage at $4{ }^{\circ} \mathrm{C}$ is presented in Table 2.

Considering all the dietary treatments, TBARS values were found to increase strongly with time of storage. However, low values of TBARS were observed in the samples related to treatment 2 even after 8 days of storage. The lowest values of TBARS were achieved during the entire storage time using dietary vitamin $\mathrm{E}$ supplementation, indicating that vitamin $\mathrm{E}$ can efficiently prevent lipid oxidation in meat from broilers. The use of dietary vitamin $\mathrm{E}$ as supplement induces the accumulation of this lipophilic antioxidant in the muscle tissue. In fact, several studies have demonstrated that increased vitamin $\mathrm{E}$ levels in the muscle enhance the protection of meat lipids against peroxidation. ${ }^{41-44}$

Samples from broilers fed without supplements showed lower levels of TBARS at 0 days of storage when compared to the samples from animals fed different levels of mate extract. However, the formation of TBARS was demonstrated to decrease proportionally to the level of dietary mate extract from 2 to 4 days of storage. Increasing levels of dietary mate extract also prevented the TBARS formation from 6 to 8 days of storage, however, samples from T5 with the highest level of mate extract showed higher levels of TBARS when compared to samples from the other treatments that used mate as dietary supplement.

Based on these results, the use of natural antioxidants such as vitamin $\mathrm{E}$ or mate as dietary supplement is concluded to have a significant effect in preventing lipid oxidation in muscle tissue. Despite that, the trend observed for TBARS values does not follow the kinetics behavior that was found for the formation of radicals in meat slurries as probed by EPR spin-trapping. Such difference may be explained taking into account that lipid peroxidation alone does not provide information on the total redox status of meat. Besides lipids, several other meat compounds take part in oxidative reactions and contribute to the resistance of meat to oxidation. Interactions among all meat components may affect the pathways for the production of reactive oxygen species (ROS) and reactive nitrogen species (RNS) and, consequently, for meat quality deterioration. Zawadzki et al..$^{33}$ reported the effect of hop $\beta$-acids as dietary supplement in preventing the oxidation of myofibrillar proteins and polyunsaturated fatty acids from chicken meat. Vitamin $\mathrm{E}$ was shown to accumulate in the muscle tissue protecting meat fatty acids against oxidation. On the other hand, mate extract seems to modulate animal metabolism and protect hydrophilic compounds against oxidation. Additional analyses must be undertaken in order to investigate the effect of dietary mate extract in modulating the lipid profile of meat from chicken.

\section{Conclusions}

The use of antioxidant supplements like mate extract in animal diet appears to improve the redox status of meat by changing its metabolic profile towards the production of endogenous antioxidants and other compounds that are of importance for meat quality and storage stability. Synergistic effects between the natural antioxidants found in meat may prevent nutritional loss and quality deterioration. The type of supplement and the manipulation of the levels of the supplement have both shown to be a nutritional strategy to achieve a better meat product. For chicken, moderate levels of supplement seem to improve the metabolic profile by increasing the levels of endogenous antioxidants. Large doses overshoot the effect showing even signs of toxicity. A similar pattern is also seen for lipid oxidation during meat storage for longer periods of time, where high levels of mate extract in the feed increase lipid oxidation relative to moderate levels. 


\section{Supplementary Information}

Supplementary information (mean concentration of polar metabolites in meat extracts from broilers fed different levels of mate extract and control animals, typical ${ }^{1} \mathrm{H}$ NMR spectrum of meat extract from chicken fed different levels of mate extract, and typical EPR spectrum of meat extract from chicken fed different levels of mate extract) is available free of charge at http://jbcs.sbq.org.br as PDF file.

\section{Acknowledgments}

This research has been done through the collaboration between Brazil and Denmark in the Food Science Research Program "BEAM - Bread and Meat for the Future" which involved University of Copenhagen and Universidade de São Paulo. The research program was granted by FAPESP (grant 2011/51555-7), by the Danish Research Council for Strategic Research (grant 11-116064), and by the Brazilian National Research Council (CNPq, grants 305385/2009-7 and 141525/2013-4). Authors thank Prof Menten from the Escola Superior de Agricultura "Luiz de Queiroz" (ESALQ) for kindly providing meat samples from animal feeding trials.

\section{References}

1. Shah, M. A.; Bosco, S. J. D.; Mir, S. A.; Meat Sci. 2014, 98, 21.

2. Hernández, F.; Madrid, J.; García, V.; Orengo, J.; Megías, M. D.; Poult. Sci. 2004, 83, 169.

3. Greathead, H.; Proc. Nutr. Soc. 2003, 62, 279.

4. García, V.; Catalá-Gregori, P.; Hernández, F.; Megías, M. D.; Madrid, J.; J. Appl. Poult. Res. 2007, 16, 555.

5. Smet, K.; Raes, K.; Huyghebaert, G.; Haak, L.; Arnouts, S.; De Smet, S.; Poult. Sci. 2008, 87, 1682

6. Jongberg, S.; Torngren, M. A.; Gunvig, A.; Skibsted, L. H.; Lund, M. N.; Meat Sci. 2013, 93, 538.

7. Bortoluzzi, C.; Menten, J. F. M.; Romano, G. G.; Pereira, R.; Napty, G. S.; Poult. Sci. 2014, 23, 437.

8. Zhang, W.; Xiao, S.; Samaraweera, H.; Lee, E. J.; Ahn, D. U.; Meat Sci. 2010, 86, 15.

9. Kumar, Y.; Yadav, D. N.; Ahmad, T.; Narsaiah, K.; Compr. Rev. Food Sci. Food Saf. 2015, 14, 796.

10. Arihara, K.; Meat Sci. 2006, 74, 219.

11. Jongberg, S.; Torngren, M. A.; Skibsted, L. H.; Medicines 2018 , 5, 1. DOI 10.3390/medicines5010011.

12. Jongberg, S.; Torngren, M. A.; Skibsted, L. H.; Medicines 2018 , 5, 2. DOI 10.3390/medicines5010007.

13. Zawadzki, A.; Arrivetti, L. O. R.; Vidal, M. P.; Catai, J. R.; Nassu, R. T.; Tullio, R. R.; Berndt, A.; Oliveira, C. R.; Ferreira,
A. G.; Neves-Junior, L. F.; Colnago, L. A.; Skibsted, L. H.; Cardoso, D. R.; Food Res. Int. 2017, 99, 336.

14. Racanicci, A. M. C.; Danielsen, B.; Skibsted, L. H.; Eur. Food Res. Technol. 2008, 227, 255.

15. Racanicci, A. M. C.; Menten, J. F. M.; Alencar, S. M.; Buissa, R. S.; Skibsted, L. H.; Eur. Food Res. Technol. 2011, 232, 655.

16. Rostagno, H. S.; Albino, L. F. T.; Donzele, J. L.; Gomes, P. C.; Oliveira, R. T.; Lopes, D. C.; Ferreira, A. S.; Barreto, S. D. T.; Euclides, R. F.; Tabelas Brasileiras para Aves e Suínos: Composição de Alimentos e Exigências Nutricionais, $3^{\mathrm{a}}$ ed.; UFV: Viçosa, 2011.

17. Ministério da Agricultura, Pecuária e Abastecimento (MAPA); Regulamento Técnico de Métodos de Insensibilização para o Abate Humanitário de Animais de Açougue, Instrução Normativa No. 3, de 17 de Janeiro de 2000.

18. de Lima, C. B.; Racanicci, A. M. C.; Oliveira, G. R.; Migotto, D. L.; Amador, S. A.; de Souza, T. C. B. G. S.; Vieira, A.; Rev. Bras. Cienc. Avic. 2015, 17, 47.

19. Madsen, H. L.; Sørensen, B.; Skibsted, L. H.; Bertelsen, G.; Food Chem. 1998, 63, 173.

20. Chenomx Inc.; Chenomx NMR Suite 8.0 software; Chenomx Inc., Edmonton, Canada.

21. http://www.chemspider.com/, accessed in May 2018.

22. http://www.hmdb.ca/, accessed in May 2018.

23. Wishart, D. S.; Jewison, T.; Guo, A. C.; Wilson, M.; Knox, C.; Liu, Y.; Mandal, Y. D. R.; Aziat, F.; Dong, E.; Bouatra, S.; Sinelnikov, I.; Arndt, D.; Xia, J.; Liu, P.; Yallou, F.; Bjorndahl, T.; Eisner, R. P.-P. R.; Allen, F.; Neveu, V.; Greiner, R.; Scalbert, A.; Nucleic Acids Res. 2013, 41, D801.

24. Wishart, D. S.; Tzur, D.; Knox, C.; Eisner, R.; Guo, A. C.; Young, N.; Cheng, D.; Jewell, K.; Arndt, D.; Sawhney, S.; Fung, C.; Nucleic Acids Res. 2007, 35, D521.

25. Wishart, D. S.; Knox, C.; Guo, A. C.; Eisner, R.; Young, N.; Gautam, B.; Hau, D. D.; Psychogios, N.; Dong, E.; Bouatra, S.; Mandal, R.; Nucleic Acids Res. 2008, 37, D603.

26. Krishnamurthy, K.; Magn. Reson. Chem. 2013, 51, 821.

27. Hall, M.; Frank, E.; Holmes, G.; Pfahringer, B.; Reutemann, P.; Witten, I. H.; ACM SIGKDD Explor. Newsl. 2009, 11, 10.

28. Frank, E.; Hall, M. A.; Witten, I. H. In Data Mining: Practical Machine Learning Tools and Techniques, $4^{\text {th }}$ ed.; Witten, I. H.; Frank, E.; Hall, M. A.; Pal, C. J., eds; Morgan Kaufmann: San Francisco, 2016, Online Appendix. Available at https://www. cs.waikato.ac.nz/ml/weka/book.html, accessed in May 2018.

29. Liu, H.; Motoda, H.; Feature Selection for Knowledge Discovery and Data Mining, vol. 454; Springer Science \& Business Media: Heidelberg, 2012.

30. Jolliffe, I. T.; Principal Component Analysis; Springer: New York, 1986, p. 115-128.

31. Python Software Foundation; Python; Python Software Foundation, Beaverton, USA. 
32. Bjorck, A.; Numerical Methods for Least Squares Problems; Siam: Sweden, 1996.

33. Zawadzki, A.; Alloo, C.; Grossi, A. B.; Nascimento, E. S.; Almeida, L. C.; Junior, S. B.; Skibsted, L. H.; Cardoso, D. R.; Food Res. Int. 2017, 105, 210.

34. Carlsen, C.; Moller, J.; Skibsted, L.; Coord. Chem. Rev. 2005, 249, 485.

35. Carlsen, C. U.; Andersen, M. L.; Skibsted, L. H.; Eur. Food Res. Technol. 2001, 213, 170.

36. Lund, M. N.; Luxford, C.; Skibsted, L. H.; Davies, M. J.; Biochem. J. 2008, 410, 565.

37. Lund, M. N.; Heinonen, M.; Baron, C. P.; Estévez, M.; Mol. Nutr. Food Res. 2011, 55, 83.

38. Buettner, G. R.; Free Radical Biol. Med. 1987, 3, 259.

39. Moré, J. J. In Numerical Analysis; Watson, G. A., ed.; Springer: Berlin, 1978, p. 105-116.
40. Tarladgis, B. G.; Pearson, A. M.; Jun, L. R.; J. Sci. Food Agric. 1964, 15, 602.

41. Buckley, D. J.; Morrissey, P. A.; Gray, J. I.; J. Anim. Sci. 1995, 73, 3122 .

42. Kingston, E. R.; Monahan, F. J.; Buckley, D. J.; Lynch, P. B.; J. Food Sci. 1998, 63, 386.

43. Descalzo, A. M.; Insani, E. M.; Biolatto, A.; Sancho, A. M.; García, P. T.; Pensel, N. A.; Josifovich, J. A.; Meat Sci. 2005, 70,35 .

44. Luciano, G.; Moloney, A. P.; Priolo, A.; Röhrle, F. T.; Vasta, V.; Biondi, L.; López-Andrés, P.; Grasso, S.; Monahan, F. J.; J. Anim. Sci. 2011, 89, 3759.

Submitted: February 28, 2018

Published online: May 29, 2018 